\title{
Determinants of Default from Pulmonary Tuberculosis Treatment in Kuwait
}

\author{
Qing Zhang, ${ }^{1}$ Mohamed Gaafer, ${ }^{2}$ and Ibrahim El Bayoumy ${ }^{3,4}$ \\ ${ }^{1}$ Tuberculosis Diagnosis and Treatment Center, Shanghai, Pulmonary Hospital, School of Medicine, Tongji University, \\ 507 Zheng Min Road, Shanghai 200433, China \\ ${ }^{2}$ Community, Environmental and Occupational Medicine Department, Minufiya University, Egypt \\ ${ }^{3}$ Public Health Department, Tanta Faculty of Medicine, Egypt \\ ${ }^{4}$ Ports and Borders Health Division, P.O. Box 35180, 36052 Shaab, Kuwait
}

Correspondence should be addressed to Ibrahim El Bayoumy; ibrahim_elbayoumy2000@yahoo.com

Received 17 August 2013; Accepted 9 October 2013; Published 6 April 2014

Academic Editors: R. Diel and A. Khan

Copyright (C) 2014 Qing Zhang et al. This is an open access article distributed under the Creative Commons Attribution License, which permits unrestricted use, distribution, and reproduction in any medium, provided the original work is properly cited.

\begin{abstract}
Objectives. To determine the prevalence and risk factors of default from pulmonary tuberculosis treatment in Kuwait. Design. Retrospective study. Patients and methods. We studied all patients who were registered for pulmonary tuberculosis treatment between January 1, 2010, and December 31, 2012, and admitted into TB wards in El Rashid Center or treated in the outpatient clinic in TB Control Unit. Results. There were 110 (11.5\%) patients who defaulted from treatment. Fifty-six percent of those who defaulted did so in the first 2 months of treatment and $86.4 \%$ of them were still bacteriologically positive at the time of default. Key risk factors associated with noncompliance were male sex, low educational level, non-Kuwaiti nations, history of default, and history of concomitant diabetes mellitus, liver disease, or lung cancer. Multiple drug resistance was also associated with default from treatment. Conclusion. Default from treatment may be partially responsible for the persistent relatively high rates of tuberculosis in Kuwait. Health professionals and policy makers should ensure that all barriers to treatment are removed and that incentives are used to encourage treatment compliance.
\end{abstract}

\section{Introduction}

Tuberculosis is a leading cause of morbidity and mortality worldwide; 2 billion people, equal to one-third of the world's total population, are infected with TB bacilli, the microbes that cause TB [1].

In Kuwait, the incidence of tuberculosis was very high in late 1960s, at nearly 270 cases per 100000 population. The National Tuberculosis Programme (NTP) has been working hard to bring tuberculosis under control. The NTP adopted the Directly Observed Treatment Short course (DOTS) strategy in 1998, expanded it rapidly, and achieved 100\% DOTS population coverage. With the sustained efforts of the NTP and the progressive improvement in the socioeconomic situation, the notification rate of all forms and smear positive tuberculosis reached 21.1 and 9.0 per 100,000 population in 2006 (resp.). This means that 645 people developed tuberculosis last year and 274 of them were infectious (i.e., smear positive) [2].

Early diagnosis of tuberculosis and effective treatment are the key elements in reduction of transmission of infection and finally achieving elimination of TB [3]. World Health Organization (WHO) had set the international target value for a favorable treatment outcome at $85 \%$ [4]. In many industrialized countries with good treatment facilities and a secured supply of drugs free of charge for patients, treatment results have not reached the targets set by WHO yet $[5,6]$.

Treatment outcome monitoring is a core part of surveillance necessary to succeed in tuberculosis elimination [7]. The WHO has published a recommendation for assessing the outcome of tuberculosis treatment in the 1990s [8], revised recently $[9,10]$.

The specific reasons for unsuccessful outcomes are important in order to improve treatment systems. In a recent 
outcome analysis from Norway, where the large majority of TB cases are in immigrants, only high age and isoniazid (INH) resistance were significant risk factors for unsuccessful outcome [11]. In earlier studies, high age, alcoholism, HIV infection, male sex, and immigration have been associated with unfavorable outcomes [12].

The currently recommended minimum duration of treatment is 6 months, which, although much shorter than the previously recommended 12 to 24 months, is still very long. According to WHO, DOTS ensures successful treatment of patients with tuberculosis [13]. There are still patients who are not compliant to DOTS and default from treatment.

Poor case management, often because of nonadherence to treatment, has emerged as the most important factor in the resurgence of tuberculosis and the appearance of multiple drug resistance, MDR (resistance to two or more of the primary drugs, isoniazid and rifampin), and extensively Drug Resistance, XDR (resistance to at least isoniazied and rifampin among the first-line anit-TB drugs and among second-line drugs, is resistant to any fluoroquinolone and at least one of three injectable drugs) [14]. The prolonged duration of treatment, the need for multiple drugs, and socioeconomic factors are the main reasons for nonadherence to treatment.

This study aims to assess the determinants and predictors of default from pulmonary tuberculosis treatment in Kuwait.

\section{Patients and Methods}

The State of Kuwait is located in the Gulf area and has a population of approximately 3.3 million, $68 \%$ of whom are expatriates seeking residency for work [15]. 60\% of residents come from South East Asia where tuberculosis is endemic and constitutes $40-45 \%$ of worldwide TB cases [16].

We studied all patients who were registered for pulmonary tuberculosis treatment between January 1, 2010 and December 31, 2012 and admitted in TB wards in El Rashid Center or treated in theoutpatient clinic in TB Control Unit. These governmental facilities concentrate the treatment of all pulmonary TB patients around the country.

Default was defined as failure to collect medication for more than 2 consecutive months after the date of the last attendance. To examine the determinants and risk factors of default from treatment, we used a nested case control study design. For each case of default (110 cases), three controls were randomly selected (330 controls) from cases that cured or completed treatment, using computer-generated random numbers.

Data of patients treated were obtained from programme forms (treatment cards) that were submitted by chest physicians at the onset of pulmonary tuberculosis treatment and thereafter. The forms had the following information: patient name, starting date of treatment, age, sex, history of treatment, the extent of disease, and the case category (new, relapse, treatment after default, and treatment after failure). The forms also listed the type of drug regimen used, the frequency of drug treatment, side effects, bacteriological status before treatment and at 2 and 5 or 6 months from the start of treatment, drug sensitivity of microorganisms, and the treatment outcome. In addition, we reviewed medical records at TB Control Unit for patients with missing forms, missing information, and inconsistent information between forms. The definitions used in this study were modified from those according to the International Union Against Tuberculosis and Lung Diseases (IUATLD) [17].

2.1. Statistical Analysis. The data were analyzed using the Statistical Package for the Social Sciences (Windows version 12; SPSS Inc., Chicago, US). The differences in clinical features between the cases of default and the controls were tested by Chi squared analysis. Multiple logistic regression was used to analyze the association between various risk factors and treatment default. This study was approved by the Ethics Committee of NTP.

\section{Results}

See Tables 1, 2, 3, 4, and 5 .

\section{Discussion}

In Kuwait, the policy of National Tuberculosis Program (NTP) is to manage all cases of pulmonary tuberculosis with DOTS strategy in two governmental facilities, outpatient clinic in TB Control Unit, and TB wards in El Rashid Center. The cost of drug treatment is not an issue in Kuwait, because all antituberculous drugs are free of charge for both Kuwaiti and non-Kuwaiti. The infrastructure for DOTS in Kuwait is very good.

Default from treatment is unlikely to be solely responsible for the current stagnant rate of tuberculosis at a relatively high level. One hundred and ten $(11.5 \%)$ of patients who registered for treatment of pulmonary tuberculosis between January 1, 2010 and December 31, 2012 defaulted from treatment. $86.4 \%$ of them had positive results to smear or culture tests, indicating that they were still potentially infectious. However, the treatment Cure Rate (with exclusion of who left the country) was about $88.6 \%$, which reaches the target set by the WHO for treatment completion [1].

According to published studies, one smear and culture positive patient with pulmonary tuberculosis infects, on average, about twelve others each year, while each culture positive patient infects two others [18]. Hence, the patients who defaulted from treatment in study period might have infected 780 individuals in the first year after default from treatment. Furthermore, about $10 \%$ to $15 \%$ of infected individuals develop the disease after infection and half of them may be infectious and in turn can transmit the disease to others [19]. So, these defaulters might have added substantially to the pool of infectious people.

Because of other factors, such as death, natural remission, retreatment of some cases, and the effect of partial treatment on the viability of the bacilli, it is impossible to detect exactly the impact of default from treatment to the overall rate of tuberculosis in Kuwait. But the mean duration of infectivity of each case of tuberculosis is estimated to be 2 years [17], so 
TABLE 1: Outcome of pulmonary tuberculosis treatment by sputum smear status (for the years 2004-2006).

\begin{tabular}{|c|c|c|c|}
\hline Treatment outcome & Smear positive & Smear negative & Total \\
\hline Cured & $318(44.3)$ & - & $318(33.4)$ \\
\hline Completed & $178(24.8)$ & $180(76.3)$ & $358(37.5)$ \\
\hline Died & $5(0.7)$ & $0(0.0)$ & $5(0.5)$ \\
\hline Failed & $0(0.0)$ & $0(0.0)$ & $0(0.0)$ \\
\hline Defaulted & $59(8.2)$ & $51(21.6)$ & $110(11.5)$ \\
\hline Left the country & $158(22.0)$ & $5(2.1)$ & $163(17.1)$ \\
\hline Total registered & $718(100.0)$ & $236(100.0)$ & $954(100.0)$ \\
\hline
\end{tabular}

Out of the 954 patients who were treated for tuberculosis in the study period, 110 (11.5\%) refused treatment or failed to attend the clinic for more than 2 consecutive months, thereby fulfilling the criteria for treatment default. One hundred fifty-eight smear positive TB cases ( $22.0 \%$ of smear positive) were new comer expatriates; they had taken antituberculous medications until sputum is converted, to be noninfectious during transportation, and then deported to their countries. Cure Rate (cured plus completed) for smear positive cases $=88.6 \%$ (with exclusion of who left the country) and $69.1 \%$ (without exclusion of who left the country).

TABLE 2: Demographic characteristics of defaulters and nondefaulters.

\begin{tabular}{|c|c|c|c|}
\hline Variables & Defaulters $(n=110)$ & Nondefaulters $(n=330)$ & $P$ value \\
\hline \multicolumn{4}{|l|}{ Age group (years): } \\
\hline $0-19$ & $4(3.6)$ & $15(4.6)$ & \multirow{4}{*}{0.18 (NS) } \\
\hline $20-39$ & $45(40.9)$ & $115(34.8)$ & \\
\hline $40-59$ & $39(35.5)$ & $100(30.3)$ & \\
\hline$\geq 60$ & $22(20.0)$ & $100(30.3)$ & \\
\hline \multicolumn{4}{|l|}{ Sex: } \\
\hline Female & $26(23.6)$ & $125(37.8)$ & \multirow{2}{*}{0.006} \\
\hline Male & $84(76.4)$ & $200(62.2)$ & \\
\hline \multicolumn{4}{|l|}{ Nationality: } \\
\hline Kuwaiti & $4(20.9)$ & $50(15.1)$ & \multirow{2}{*}{0.002} \\
\hline Non-Kuwaiti & $106(79.1)$ & $280(84.9)$ & \\
\hline \multicolumn{4}{|l|}{ Educational status: } \\
\hline Undergraduate & $88(80.0)$ & $185(56.1)$ & \multirow{2}{*}{$<0.0001$} \\
\hline Graduate and above & $22(20.0)$ & $145(43.9)$ & \\
\hline \multicolumn{4}{|l|}{ Marital status: } \\
\hline Single & $71(64.5)$ & $187(56.7)$ & \multirow{4}{*}{0.12 (NS) } \\
\hline Married & $20(18.2)$ & $98(29.7)$ & \\
\hline Divorced & $11(10.0)$ & $28(8.5)$ & \\
\hline Widowed & $8(7.3)$ & $17(5.1)$ & \\
\hline \multicolumn{4}{|l|}{ Case category: } \\
\hline New case & $90(81.8)$ & $290(87.9)$ & 0.15 (NS) \\
\hline Treatment after default & $14(12.7)$ & $6(1.8)$ & $<0.0001$ \\
\hline Relapse & $2(1.8)$ & $10(3.0)$ & $0.74(\mathrm{NS})$ \\
\hline Others & $4(3.6)$ & $24(7.3)$ & $0.26(\mathrm{NS})$ \\
\hline Concomitant illness: & $23(\mathbf{2 0 . 9 )}$ & $21(6.4)$ & $<0.0001$ \\
\hline Diabetes mellitus & $11(10.0)$ & $13(3.9)$ & 0.02 \\
\hline Liver disease as fibrosis & $6(5.4)$ & $4(1.2)$ & 0.02 \\
\hline Lung cancer & $4(3.6)$ & $1(0.3)$ & 0.02 \\
\hline Renal disease & $2(1.8)$ & $3(0.9)$ & $0.79(\mathrm{NS})$ \\
\hline
\end{tabular}

There was no significant difference in age or marital status between defaulters and nondefaulters. The defaulted group had more men than women, a higher proportion with low educational level $(80.0 \%)$, and a history of default compared with the control group. The difference was statistically significant $(P<0.05)$. Regarding nationality, defaulting was more frequently encountered among non-Kuwaiti than Kuwaiti (79.1\% and 20.9\%, resp.). Non Kuwaiti defaulters including Indian (40.9\%), Bangladeshi (20.9\%), Indonesian (13.6\%), Pakistani (10\%), Philippine (6.4\%), and other nationalities (4.6\%).

A higher proportion of cases than of controls had concomitant illnesses; the proportion with diabetes, liver diseases, and lung cancers were higher among those who defaulted from treatment $(P<0.05)$. 
TABLE 3: Extent of disease, cavitation, bacteriology, and drug susceptibility pattern among defaulters and nondefaulters.

\begin{tabular}{|c|c|c|c|}
\hline Variables & Defaulters $(n=110)$ & Nondefaulters $(n=330)$ & $P$ value \\
\hline \multicolumn{4}{|l|}{ Extent of disease: } \\
\hline Minimal & $66(60.0)$ & $210(63.6)$ & \multirow{3}{*}{$0.96(\mathrm{NS})$} \\
\hline Moderate & $32(29.1)$ & $85(28.8)$ & \\
\hline Advanced & $12(10.9)$ & $29(11.8)$ & \\
\hline Cavitary disease: & $22(20.0)$ & $65(19.7)$ & 0.83 (NS) \\
\hline \multicolumn{4}{|l|}{ Bacteriological status: } \\
\hline Smear and culture positive & $43(39.1)$ & $128(38.8)$ & \multirow{4}{*}{$0.92(\mathrm{NS})$} \\
\hline Smear positive only & $16(14.6)$ & $57(17.3)$ & \\
\hline Culture positive only & $36(32.7)$ & $102(30.9)$ & \\
\hline Smear and culture negative & $15(13.6)$ & $43(13.0)$ & \\
\hline \multicolumn{4}{|l|}{ Drug susceptibility: } \\
\hline Fully sensitive & $97(88.2)$ & $295(89.4)$ & \multirow{3}{*}{0.79 (NS) } \\
\hline Resistant to one first-line drug & $9(8.2)$ & $27(8.2)$ & \\
\hline Resistant to more than one first-line drug & $4(3.6)$ & $8(2.4)$ & \\
\hline Multiple drug resistance: & $4(3.7)$ & $1(0.3)$ & 0.01 \\
\hline
\end{tabular}

TABLE 4: Distribution of defaulters by time of default and bacteriological status.

\begin{tabular}{|c|c|c|c|c|c|}
\hline Start time of treatment & $\begin{array}{c}\text { Smear and } \\
\text { culture positive }\end{array}$ & Smear positive & Culture positive & $\begin{array}{c}\text { Smear and } \\
\text { culture negative }\end{array}$ & Total \\
\hline No treatment & $1(2.3)$ & $0(0.0)$ & $2(5.6)$ & $0(0.0)$ & $3(2.7)$ \\
\hline$<2$ weeks & $3(7.0)$ & $4(25.0)$ & $3(8.3)$ & $2(13.3)$ & $12(10.9)$ \\
\hline 2 weeks -2 months & $16(37.2)$ & $9(56.3)$ & $19(52.8)$ & $3(20.0)$ & $47(42.7)$ \\
\hline 2 weeks -4 months & $10(23.3)$ & $2(12.5)$ & $8(22.2)$ & $3(20.0)$ & $23(20.9)$ \\
\hline$>4$ months & $13(30.2)$ & $1(6.2)$ & $4(11.1)$ & $7(46.7)$ & $25(22.8)$ \\
\hline Total & $43(39.1)$ & $16(14.6)$ & $36(32.7)$ & $15(13.6)$ & $110(100.0)$ \\
\hline
\end{tabular}

Approximately $56 \%$ of patients who defaulted did so within the first 2 months of treatment. Of the 110 patients who defaulted, 95 (86.4\%) were still bacteriologically positive ( 43 smear and culture positive, 16 smear positive, and 36 culture positive only) at the time of default.

the additional annual risk of infection attributable to patients who defaulted from treatment in Kuwait is about $0.02 \%$.

In this study, we found that a history of default from treatment is the strongest predictor of non-compliance, followed by the presence of concomitant diabetes mellitus, liver disease, lung cancer, low educational level, male sex, and non-Kuwaiti nationalities. Defaulting was more frequently encountered among non-Kuwaiti than Kuwaiti (79.1\% and $20.9 \%$, resp.), especially those coming from south East Asia, where TB is endemic and constitutes $40-45 \%$ of worldwide TB cases [20]: Indian (40.9\%), Bangladeshi (20.9\%), Indonesian (13.6\%), Pakistani (10\%), Philippine (6.4\%), and other nationalities $(4.6 \%)$.

Most published studies had shown that HIV infection, homelessness, smoking, alcohol and drug misuse, psychiatric illness, and poverty are all risk factors for noncompliance to treatment [21]. In our study, these data were not available in the programme forms.

The risk of MDR tuberculosis was significantly higher among defaulters than non-defaulters, which is consistent with most of the published results [22]. This finding is especially worrisome, because all patients were still bacteriologically positive at the time of treatment default.

Legal sanction against defaulters has been attempted in the United States in the mid-1980s, when there was a dramatic rise in the rate of tuberculosis and MDR tuberculosis among HIV-infected individuals [23]. Although there was widespread support for such legal action, there were concerns that these powers might be abused for use as a means of social control, and many believed that it was unfair to detain patients when their ability to comply with treatment was affected by the lack of housing, primary health care, and services for substance users [24].

In the United Kingdom, legislation allows for the detention of an individual with a notifiable disease that is a threat to others, but this legislation is rarely used [25]. The moral issues in the use of coercion and detainment in dealing with nonadherence in the diagnosis and treatment of tuberculosis have been widely debated [26, 27]. Although coercion and detainment have been found by ethicists to be a morally 
TABLE 5: Odds ratios from multiple logistic regression analysis, examining the association between selected risk factors and treatment default.

\begin{tabular}{|c|c|c|c|}
\hline Variables & Odds ratio & 95\% confidence interval & $P$ value \\
\hline Age (years) & 0.95 & $0.96-1.1$ & $0.56(\mathrm{NS})$ \\
\hline \multicolumn{4}{|l|}{ Sex: } \\
\hline Male versus female & 1.3 & $1.2-1.7$ & 0.03 \\
\hline \multicolumn{4}{|l|}{ Educational status: } \\
\hline Undergraduate versus graduate and above & 1.9 & $1.6-4.3$ & 0.01 \\
\hline \multicolumn{4}{|l|}{ Nationality: } \\
\hline Non-Kuwaiti versus Kuwaiti & 2.4 & $1.9-6.4$ & 0.01 \\
\hline \multicolumn{4}{|l|}{ Cavitation: } \\
\hline Yes versus no & 0.9 & $0.7-1.5$ & $0.81(\mathrm{NS})$ \\
\hline \multicolumn{4}{|l|}{ Case category: } \\
\hline Relapse versus new case & 0.8 & $0.5-1.4$ & 0.74 (NS) \\
\hline Previous default versus new case & 1.6 & $1.1-2.9$ & 0.01 \\
\hline \multicolumn{4}{|l|}{ Extent of disease: } \\
\hline Moderate versus minimal & 0.8 & $0.6-1.4$ & 0.66 (NS) \\
\hline Advanced versus minimal & 0.6 & $0.5-1.2$ & 0.74 (NS) \\
\hline \multicolumn{4}{|l|}{ Concomitant illness: } \\
\hline Diabetes: yes versus no & 1.6 & $1.8-4.4$ & 0.03 \\
\hline Liver disease: yes versus no & 1.4 & $1.2-3.3$ & 0.04 \\
\hline Lung cancer: yes versus no & 1.3 & $1.1-2.7$ & 0.04 \\
\hline Renal disease: yes versus no & 0.9 & $0.6-1.2$ & 0.35 (NS) \\
\hline \multicolumn{4}{|l|}{ Drug susceptibility: } \\
\hline Multiple drug resistance versus fully sensitive & 2.1 & $1.3-5.6$ & 0.01 \\
\hline
\end{tabular}

Multiple logistic regression analyses were performed to determine the risk factors associated with default among those with pulmonary tuberculosis. The important risk factors associated with default included male sex (odds ratio $[\mathrm{OR}]=1.3 ; 95 \%$ confidence interval $[\mathrm{CI}], 1.2-1.7)$, low educational level $(\mathrm{OR}=1.9$; $95 \% \mathrm{CI}, 1.6-4.3)$, non-Kuwaiti nations $(\mathrm{OR}=2.4 ; 95 \% \mathrm{CI}, 1.9-6.4)$, a history of default $(\mathrm{OR}=1.6$; 95\% CI, 1.1-2.9), diabetes mellitus $(\mathrm{OR}=1.6 ; 95 \% \mathrm{CI}, 1.8-4.4)$, liver disease $(\mathrm{OR}=1.4 ; 95 \% \mathrm{CI}, 1.2-3.3)$, and lung cancer $(\mathrm{OR}=1.3 ; 95 \% \mathrm{CI}, 1.1-2.7)$.

acceptable strategy to fight the spread of tuberculosis, their use to support strategies that improve treatment compliance must be sensitive to national and cultural differences and not simply be based on perceived successes elsewhere.

Due regard must be paid to the possibility that such negative measures may aggravate the social stigma and discrimination which still surround this important airborne disease. Even if we can achieve $100 \%$ case detection, the strategy will still not work unless patients come forward for treatment.

On the other hand, it has been shown that successful DOT programmes with a high rate of treatment completion (86\%97\%) are those that provide incentives such as shelter for the homeless, methadone and rehabilitation programmes for drug abusers, food coupons, and money for transportation; some programmes also provide educational opportunities, while others make use of occupation settings to administer the drugs $[28,29]$. Directly observed therapy programmes without such incentives are less successful, with treatment completion rate of $85.0 \%$ to $87.5 \%$ [30].

The current DOT programme in Kuwait uses a combination of incentives and enablers, which include education for patients and their families, referrals for other social services, as well as use of outreach teams, and the tracing of defaulters. Greater efforts are required in the education of the patients and public to increase their understanding of the importance of treatment completion for patients with tuberculosis.

\section{Conflict of Interests}

The authors declare that there is no conflict of interests regarding the publication of this paper.

\section{References}

[1] WHO, "Stop TB partnership: TB any where is TB every where, stop TB fact sheet," 2006, www.stoptb.org.

[2] Department of Public Health, Ministry Of Health (MOH), Kuwait, “TB annual report,” Tech. Rep., 2006.

[3] L. Clancy, H. L. Rieder, D. A. Enarson, and S. Spinaci, "Tuberculosis elimination in the countries of Europe and other industrialized countries," European Respiratory Journal, vol. 4, no. 10, pp. 1288-1295, 1991.

[4] World Health Organization, "WHO tuberculosis programme: framework for effective tuberculosis control," Tech. Rep. WHO/TB/94.179, World Health Organization, Geneva, Switzerland, 1994.

[5] J. P. Zellweger and P. Coulon, "Outcome of patients treated for tuberculosis in Vaud County, Switzerland," International 
Journal of Tuberculosis and Lung Disease, vol. 2, no. 5, pp. 372$377,1998$.

[6] W. Wobeser, L. Yuan, M. Naus et al., "Outcome of pulmonary tuberculosis treatment in the tertiary care setting-Toronto 1992/93," Canadian Medical Association Journal, vol. 160, no. 6, pp. 789-794, 1999.

[7] D. P. Chin, K. C. Cummings, S. Sciortino et al., "Progress and problems in achieving the United States national target for completion of antituberculosis treatment," International Journal of Tuberculosis and Lung Disease, vol. 4, no. 8, pp. 744-751, 2000.

[8] R. Centis, A. Ianni, and G. B. Migliori, "Evaluation of tuberculosis treatment results in Italy, report 1998. Tuberculosis section of the National AIPO Study Group on Infectious Disease and the SMIRA Group," Monaldi Archives for Chest Disease, vol. 55, no. 4, pp. 293-298, 2000.

[9] L. P. Ormerod, N. Horsfield, and R. M. Green, “Tuberculosis treatment outcome monitoring: blackburn 1988-2000," International Journal of Tuberculosis and Lung Disease, vol. 6, no. 8, pp. 662-665, 2002.

[10] J. A. Caylà, J. A. Caminero, R. Rey, N. Lara, X. Vallés, and H. Galdós-Tangüis, "Current status of treatment completion and fatality among tuberculosis patients in Spain," International Journal of Tuberculosis and Lung Disease, vol. 8, no. 4, pp. 458464, 2004.

[11] EuroTB and the National Coordinators for Tuberculosis Surveillance in the WHO European Region, "Surveillance of tuberculosis in Europe. Report on tuberculosis cases notified in 2004," Tech. Rep., Institut de Veille Sanitaire, Saint-Maurice, France, 2006.

[12] T. Lillebaek, S. Poulsen, and A. Kok-Jensen, "Tuberculosis treatment in Denmark: treatment outcome for all Danish patients in 1992," International Journal of Tuberculosis and Lung Disease, vol. 3, no. 7, pp. 603-612, 1999.

[13] L. Trnka, D. Daňková, and F. Krejbich, "Is quarterly cohort analysis useful for assessing treatment outcomes in a low incidence country?" International Journal of Tuberculosis and Lung Disease, vol. 5, no. 3, pp. 250-256, 2001.

[14] P. Helbling, C. Medinger, E. Altpeter, P.-A. Raeber, D. Beeli, and J.-P. Zellweger, "Outcome of treatment of pulmonary tuberculosis in Switzerland in 1996," Swiss Medical Weekly, vol. 132, no. 35-36, pp. 517-522, 2002.

[15] L. P. Ormerod and R. J. Prescott, "The management of pulmonary and lymph node tuberculosis notified in England and Wales in 1998," Clinical Medicine, vol. 3, no. 1, pp. 57-61, 2003.

[16] A. Faustini, A. J. Hall, and C. A. Perucci, "Tuberculosis treatment outcomes in Europe: a systematic review," European Respiratory Journal, vol. 26, no. 3, pp. 503-510, 2005.

[17] WHO, IUATLD, and KNCV, "Revised international definitions in tuberculosis control," International Journal of Tuberculosis and Lung Disease, vol. 5, no. 3, pp. 213-215, 2001.

[18] J. F. Broekmans, G. B. Migliori, H. L. Rieder et al., "European framework for tuberculosis control and elimination in countries with a low incidence. Recommendations of the World Health Organization (WHO), International Union Against Tuberculosis and Lung Disease (IUATLD) and Royal Netherlands Tuberculosis Association (KNCV) Working Group," European Respiratory Journal, vol. 19, no. 4, pp. 765-775, 2002.

[19] J. Veen, M. Raviglione, H. L. Rieder et al., "Standardized tuberculosis treatment outcome monitoring in Europe. Recommendations of a Working Group of the World Health Organization (WHO) and the European Region of the International
Union Against Tuberculosis and Lung Disease (IUATLD) for uniform reporting by cohort analysis of treatment outcome in tuberculosis patients," European Respiratory Journal, vol. 12, no. 2, pp. 505-510, 1998.

[20] EuroTB, "Classification of treatment outcomes," WHO Euro/EuroTB Joint Data Collection-CISID, 2001.

[21] M. G. Farah, A. Tverdal, T. W. Steen, E. Heldal, A. B. Brantsaeter, and G. Bjune, "Treatment outcome of new culture positive pulmonary tuberculosis in Norway," BMC Public Health, vol. 5, article 14, 2005.

[22] D. Falzon, Y. Le Strat, F. Belghiti, and A. Infuso, "Exploring the determinants of treatment success for tuberculosis cases in Europe," International Journal of Tuberculosis and Lung Disease, vol. 9, no. 11, pp. 1224-1229, 2005.

[23] "Guide for treatment of tuberculosis for high prevalence countries. Paris: International Union Against Tuberculosis and Lung Disease," 2000.

[24] M. C. Raviglione and I. M. Smith, "XDR tuberculosisimplications for global public health," The New England Journal of Medicine, vol. 356, no. 7, pp. 656-659, 2007.

[25] Ministry Of Planning (MOP), Kuwait, Estimated Mid-Year Population Census, 2006.

[26] J. F. Broekmans, G. B. Migliori, H. L. Rieder et al., "European framework for tuberculosis control and elimination in countries with a low incidence. Recommendations of the World Health Organization (WHO), International Union Against Tuberculosis and Lung Disease (IUATLD) and Royal Netherlands Tuberculosis Association (KNCV) Working Group," European Respiratory Journal, vol. 19, no. 4, pp. 765-775, 2002.

[27] "Tuberculosis control and research strategies for the 1990s: memorandum from a WHO meeting," Bulletin of the World Health Organization, vol. 70, no. 1, pp. 17-21, 1992.

[28] D. A. Enarson, "Tuberculosis control in low-income countries," in Tuberculosis: A Comprehensive International Approach, L. Reichman and E. Herschfield, Eds., Lung Biology, Marcel Dekker, 2nd edition, 1999.

[29] A. Rouillon, S. Perdrizet, and R. Parrot, "Transmission of tubercle bacilli: the effects of chemotherapy," Tubercle, vol. 57, no. 4, pp. 275-299, 1976.

[30] Centers for Disease Control and Prevention, "Emergence of Mycobacterium tuberculosis with extensive resistance to second line drugs worldwide, 2000-2004," Morbidity and Mortality Weekly Report, vol. 55, no. 11, pp. 301-305, 2006. 


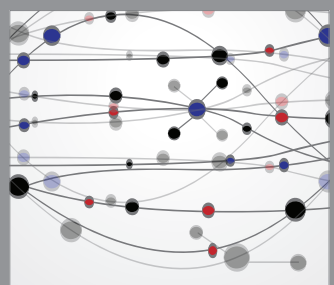

The Scientific World Journal
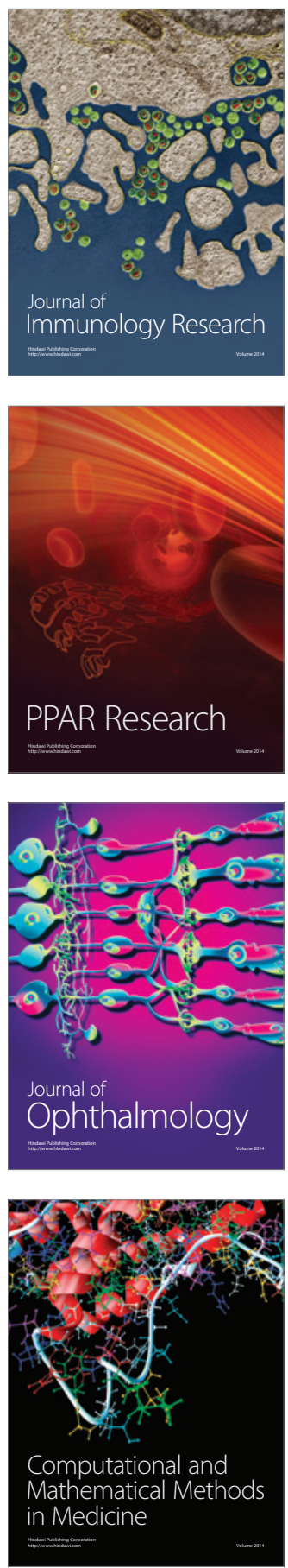

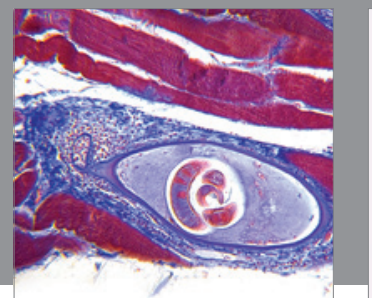

Gastroenterology

Research and Practice
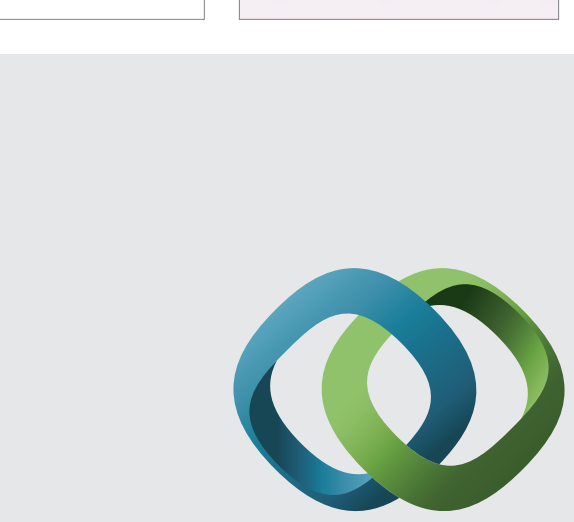

\section{Hindawi}

Submit your manuscripts at

http://www.hindawi.com
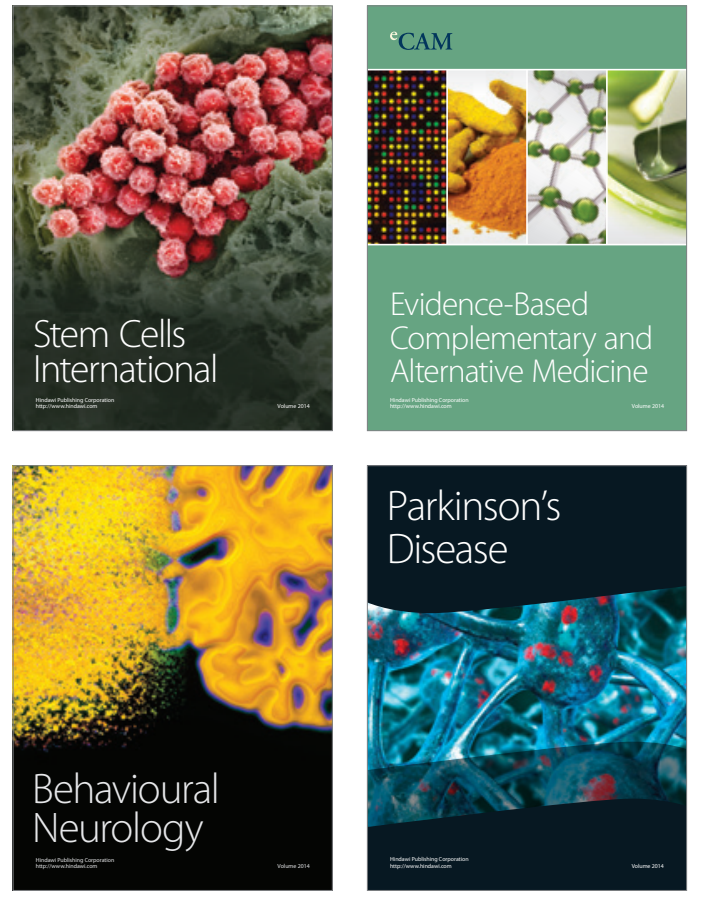
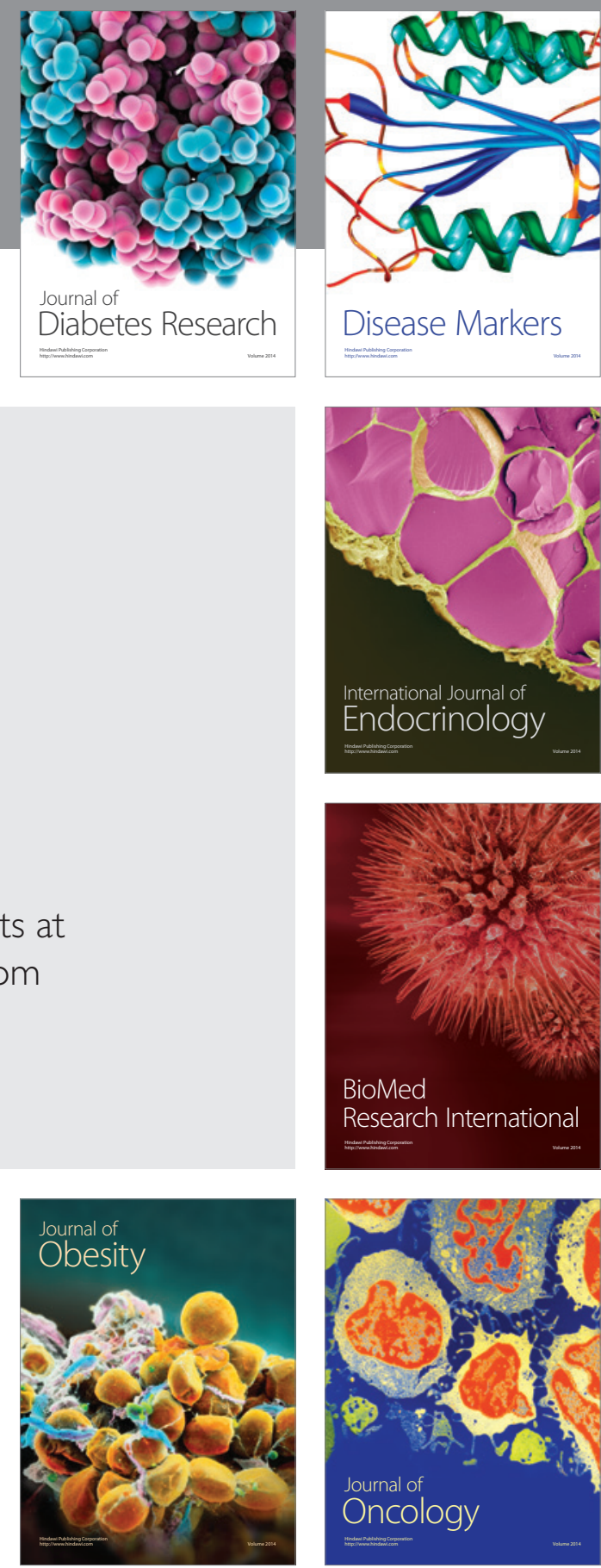

Disease Markers
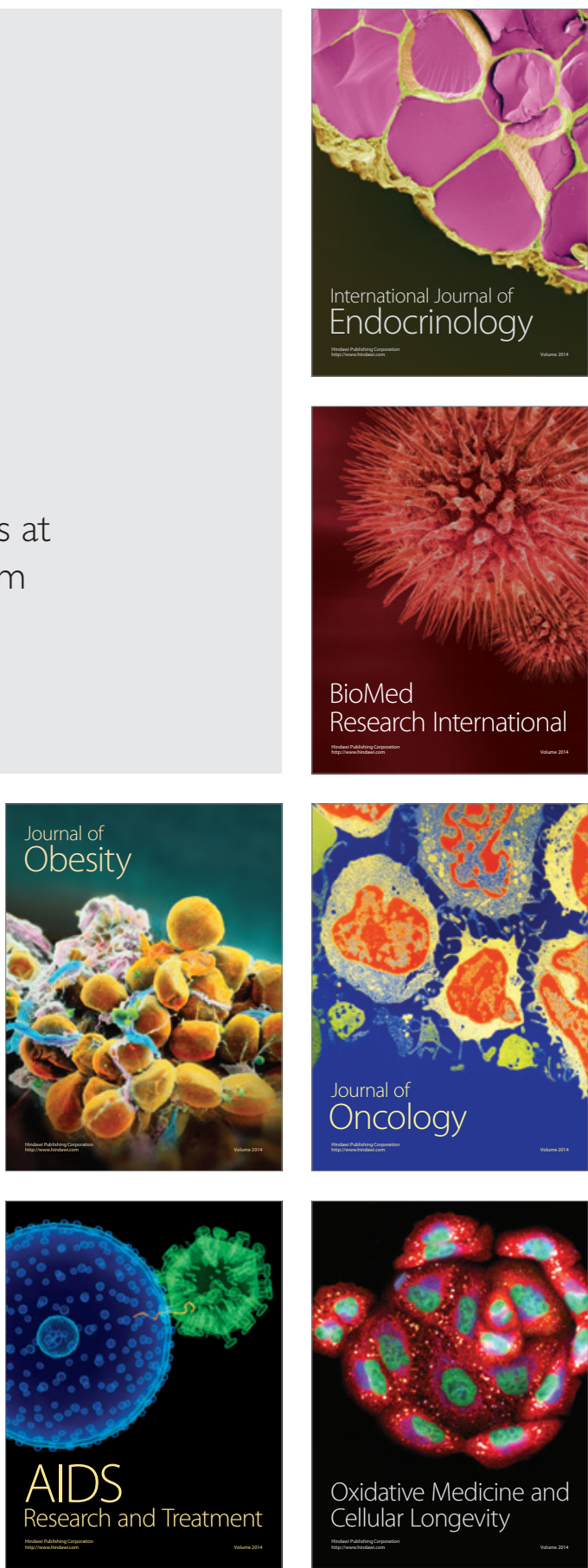